\section{First description of eosinophilic esophagitis using confocal laser endomicroscopy (with video)}
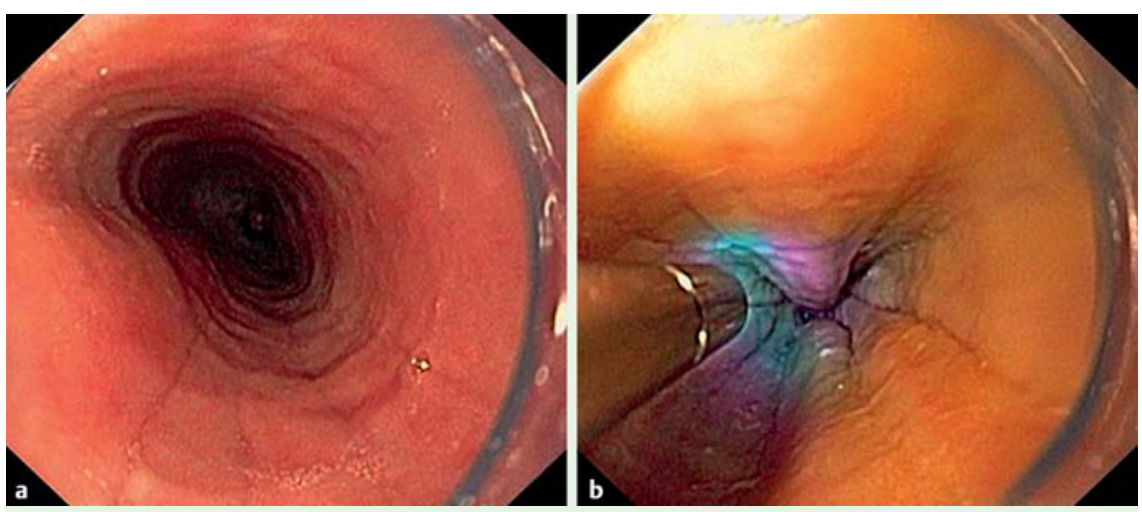

Fig. 1 a High resolution endoscopy revealed multiple coarse concentric rings throughout the entire esophagus and some narrow, long, linear channels down the esophagus. b Note the yellowish esophageal mucosa after administration of intravenous fluorescein and confocal miniprobe at the 8 o'clock position.
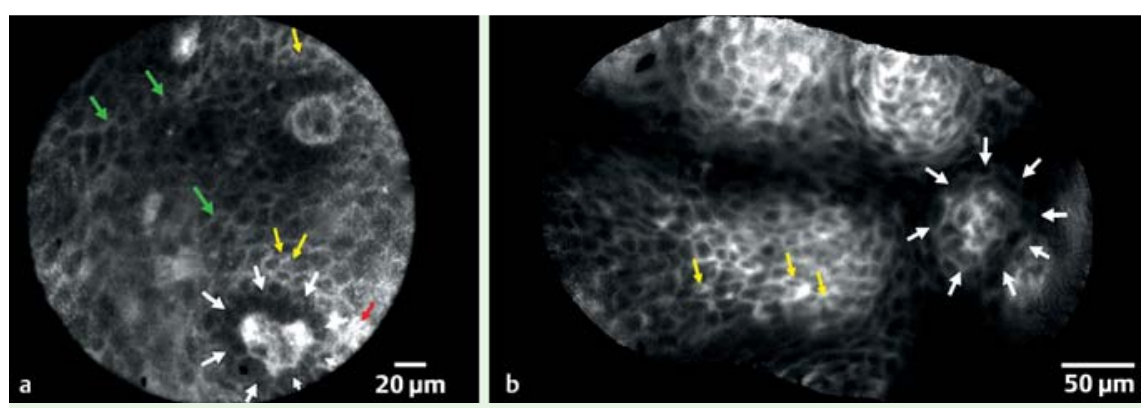

Fig. 2 a Confocal laser endomicroscopy shows dilated intercellular spaces (green arrows), leakage demonstrated by the extravasation of fluorescein (red arrow) and capillary ectasia (white arrows). b Also seen are small cells within the intercellular spaces suspicious of eosinophils (yellow arrows) and mild mucosal edema (white arrows).

Confocal laser endomicroscopy enables in vivo microscopic imaging of the mucosal layer of the gut at a subcellular resolution [1]. Various studies have addressed the potential of endomicroscopy for the in vivo diagnosis of esophageal squamous cell carcinoma, Barrett's esophagus, and esophageal adenocarcinoma [2-4]. Currently, no data are available on the utility of endomicroscopy for the in vivo diagnosis of eosinophilic esophagitis.

We report the case of an 18-year-old man who presented at our outpatient department with heartburn occurring about three times a week and mild solid food dysphagia occurring approximately two times a week. Physical examination, medical history, and routine laboratory investigations were unremarkable. Esophagogastroduodenoscopy (EGD) was performed, showing multiple coarse, concentric rings throughout the entire esophagus. In addition, some narrow, long, linear channels down the esophagus were observed scope and gently pushed against the esophageal wall ( Fig. 1b). Fluorescein guided endomicroscopy revealed dilated intercellular spaces and capillary ectasia within the esophageal squamous epithelium. In addition, leakage, demonstrated by the extravasation of fluorescein, be-

\section{Video 1}

Confocal laser endomicroscopy. See text and - Fig. 2 legend for details. came visible. Furthermore, small cells within the intercellular spaces suspicious of eosinophils and mild mucosal edema were demonstrated ( $\bullet$ Fig. 2 , Video 1 ). Based on these findings, an in vivo diagnosis of eosinophilic esophagitis was made, which was later confirmed by corresponding histopathological analysis. Subsequent to endoscopic examination the patient was put on topical steroids and remains in remission at follow-up.

In summary, our findings indicate the potential of endomicroscopy for in vivo assessment of eosinophilic esophagitis. Future prospective studies on the sensitivity and specificity of this approach are highly warranted.

Endoscopy_UCTN_Code_CCL_1AB_2AC_3AH

Competing interests: None

\section{H. Neumann ${ }^{1}$, M. Vieth ${ }^{2}$, R. Atreya ${ }^{1}$, J. Mudter ${ }^{1}$, M. F. Neurath ${ }^{1}$ \\ Department of Medicine I, University of Erlangen-Nuremberg, Erlangen, Germany 2 Institute of Pathology, Klinikum Bayreuth, Bayreuth, Germany}

\section{References}

1 Neumann $H$, Kiesslich $R$, Wallace $M B$ et al. Confocal laser endomicroscopy: technical advances and clinical applications. Gastroenterology 2010; 139: 388-392

2 Liu H, Li YQ Yu T et al. Confocal laser endomicroscopy for superficial esophageal squamous cell carcinoma. Endoscopy 2009; 41: 99-106

3 Kiesslich R, Gossner L, Goetz $M$ et al. In vivo histology of Barrett's esophagus and associated neoplasia by confocal laser endomicroscopy. Clin Gastroenterol Hepatol 2006; 4: 979-987

4 Bajbouj M, Vieth M, Rösch $T$ et al. Probebased confocal laser endomicroscopy compared with standard four-quadrant biopsy for evaluation of neoplasia in Barrett's esophagus. Endoscopy 2010; 42: 435 - 440

\section{Bibliography}

DOI $10.1055 / \mathrm{s}-0030-1255904$

Endoscopy 2011; 43: E66

(c) Georg Thieme Verlag KG Stuttgart · New York ISSN 0013-726X

\section{Corresponding author}

\section{H. Neumann, MD}

Department of Medicine I

University of Erlangen-Nuremberg

Ulmenweg 18

91054 Erlangen

Germany

Fax: +49-9131-85-35209

helmut.neumann@uk-erlangen.de 